SILVA, A.A.M.et al. Prevalência e distribuição clínica de lesões digitais em vacas da raça Holandesa mantidas em sistema "free-stall". PUBVET, Londrina, V. 4, N. 7, Ed. 112, Art. 756, 2010.

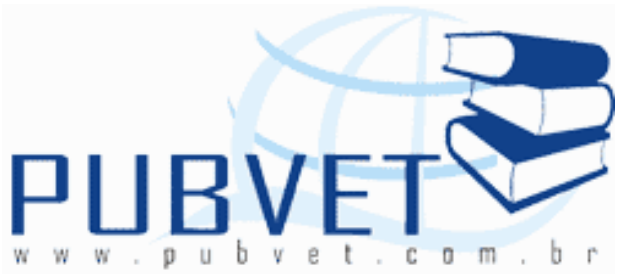

PUBVET, Publicações em Medicina Veterinária e Zootecnia.

\title{
Prevalência e distribuição clínica de lesões digitais em vacas da raça Holandesa mantidas em sistema "free-stall"
}

Ana Alice Medeiros da Silva ${ }^{1}$; José Paes de Oliveira Filho ${ }^{2 *}$; Andreza Pimenta-
Oliveira $^{2}$; Peres Ramos Badial ${ }^{2 * *}$; Paulo Henrique Jorge da Cunha ${ }^{2 *} ;$ Francisco Armando Azevedo de Souza ${ }^{3}$

${ }^{1}$ Médica Veterinária Autônoma

${ }^{2}$ Pós-graduando da Faculdade de Medicina Veterinária e Zootecnia de Botucatu

- Unesp. *Bolsista da Fundação de Amparo a Pesquisa no Estado de São Paulo

- FAPESP. ${ }^{* *}$ Bolsista da Coordenação de Aperfeiçoamento de Pessoal de Nível Superior - CAPES.

${ }^{3}$ Professor Faculdades Integradas de Ourinhos.

Autor para correspondência (Jose Paes Oliveira Filho): Departamento de Clínica Veterinária da Faculdade de Medicina Veterinária e Zootecnia - Unesp, Campus de Botucatu. Distrito de Rubião Jr. S/N CEP 18618-000- Botucatu - São Paulo. e-mail: zep.filho@hotmail.com

\section{Resumo}

Este estudo foi conduzido com o objetivo de avaliar a prevalência, a distribuição clínica das lesões digitais e estabelecer o escore de claudicação em vacas em lactação da raça Holandesa mantidas em sistema "free-stall", sendo os grupos formados por 34 primíparas (Grupo P) e 51 multíparas. Todos os 85 animais examinados apresentavam algum tipo de lesão podal. Do total de 672 
SILVA, A.A.M.et al. Prevalência e distribuição clínica de lesões digitais em vacas da raça Holandesa mantidas em sistema "free-stall". PUBVET, Londrina, V. 4, N. 7, Ed. 112, Art. 756, 2010.

lesões encontradas no grupo P, $373(55,5 \%)$ eram localizadas nos membros pélvicos. No grupo M foram observadas 927 lesões, com predomínio destas também nos membros pélvicos 536 (58\%). As lesões mais frequentemente observadas foram erosão axial, sola dupla, erosão de talão, doença da linha branca e laminite. Existiu correlação entre a presença de lesão podal e claudicação apenas nos animais do grupo M.

Palavras chave: casco, claudicação, lesões digitais, vacas de leite.

\title{
Prevalence and clinical distribution of digital lesions in Holstein cows housed in free-stall system
}

\begin{abstract}
This experiment was conducted to evaluate the prevalence, clinical distribution of digital lesions and establish score to lameness in 34 primiparous (group P) and 51 multiparous (group M) lactating Holstein cows in free-stall system. Every 85 examined cows have presented some type of injury. From a total of 672 injuries found on the group P, $373(55.5 \%)$ were on the hind limbs, on the group M, from a total of 927 injuries, $536(57.8 \%)$ on the hind limbs. The most observed affections in both groups were axial erosion, double soles, heel erosion, white line disease and laminitis. There was correlation among the presence of injury and lameness only in group $M$.

Keywords: dairy cattle, digital lesions, hoof, lameness.

INTRODUÇÃO

A incidência de enfermidades que acometem o dígito dos bovinos tem crescido nas últimas décadas, em decorrência da intensificação da atividade pecuária, principalmente sob condições precárias de higiene, umidade excessiva e acúmulo de matéria orgânica. ${ }^{1}$ No Brasil, o impacto direto dessas enfermidades foi de $R \$ 100,00$ por vaca alojada/ano, e quando se computou
\end{abstract}


SILVA, A.A.M.et al. Prevalência e distribuição clínica de lesões digitais em vacas da raça Holandesa mantidas em sistema "free-stall". PUBVET, Londrina, V. 4, N. 7, Ed. 112, Art. 756, 2010.

os custos adicionais decorrentes de seqüelas de manqueira este foi em torno de $R \$ 250,00$ por vaca alojada/ano. ${ }^{2}$

Fatores genéticos, ambientais e nutricionais, além da presença de agentes patogênicos, acúmulo de matéria orgânica e eventuais traumas digitais, estão envolvidos com a etiologia das enfermidades podais em bovinos. ${ }^{3,4}$ Embora as doenças podais tenham origem multifatorial, existe uma relação direta da incidência destas doenças com os sistemas de produção intensivos, com o número de partos, o nível de produção de leite e com a idade dos animais. ${ }^{5}$ Aproximadamente $90 \%$ das alterações do sistema locomotor de bovinos são em decorrência de lesões podais. ${ }^{6,7}$

Estudos nacionais apontam que a prevalência das lesões podais em vacas leiteiras seja em torno de $30 \%,{ }^{2,3}$ contudo, um estudo constatou que os animais de 63 propriedades leiteiras, no município de Belo Horizonte - MG, apresentavam lesões digitais. ${ }^{4}$ Essa alta prevalência provavelmente se deu pelo grande número de fatores predisponentes encontrados nestas propriedades. $^{4}$

Entre as principais enfermidades podais que acometem os bovinos destacam-se a dermatite digital, pododermatite necrosante, flegmão interdigital, pododermatite interdigital, laminite, dermatite interdigital, úlcera de sola e deformações dos cascos. ${ }^{2,3,8} \mathrm{Em}$ vista da etiologia multifatorial e das perdas econômicas importantes ocasionadas pelas enfermidades podais em bovinos, o presente estudo visa determinar a prevalência de lesões digitais, sua distribuição clínica e escore de claudicação em vacas leiteiras primíparas e multíparas, da raça Holandesa mantidas em sistema "Free-Stall".

\section{MATERIAL E MÉTODOS}

Foram selecionadas aleatoriamente 34 vacas primíparas em lactação, da raça Holandesa, com idade média de 3 anos, (Grupo P), e 51 vacas multíparas em lactação, da mesma raça, com idade entre 4 e 10 anos, (Grupo M). Os animais estudados, oriundos de uma propriedade de exploração leiteira 
SILVA, A.A.M.et al. Prevalência e distribuição clínica de lesões digitais em vacas da raça Holandesa mantidas em sistema "free-stall". PUBVET, Londrina, V. 4, N. 7, Ed. 112, Art. 756, 2010.

localizada no município de São Pedro - SP, dos grupos P e M representavam $50 \%$ e $20 \%$, respectivamente, dos animais de cada ordem existente na propriedade, sendo este percentual determinado segundo estudo previamente realizado. ${ }^{1}$

O período experimental foi compreendido entre os meses de agosto e novembro de 2006. Durante o período experimental avaliou-se a produção de leite dos animais estudados. O manejo da propriedade adotava o casqueamento dos animais (apenas membros pélvicos) no início do período seco. Contudo, quando alterações podais eram evidentes, em qualquer membro, os animais eram casqueados imediatamente, independentemente da fase de lactação que os mesmos se encontravam. Duas vezes por semana os animais, ao retornarem da ordenha, passavam por pedilúvio com formalina a $5 \%$. A alimentação das vacas em lactação seguia o sistema de ração total.

Após a composição dos grupos, cada animal foi examinado quanto à presença de claudicação, sendo a mesma classificada quanto à severidade (Tabela 1). Em seguida, os animais foram contidos, os dígitos foram examinados $^{5}$ e as lesões visualizadas foram classificadas ${ }^{1}$ e registradas em prontuário individual. Os dados encontrados, bem como a comparação entre os dois grupos estudados foram analisados de forma descritiva.

Tabela 1. Classificação da claudicação em vacas leiteiras segundo Berry (2001).

$$
\text { CARACTERÍSTICAS DA MARCHA }
$$

Grau I Sem alterações, os passos são seguros com boa distribuição do peso

Grau II Locomoção levemente alterada

Grau III Passos alterados em um ou mais membros

Grau IV Caminha mancando favorecendo um ou mais membros

Grau V Não apóia um ou mais membros 
SILVA, A.A.M.et al. Prevalência e distribuição clínica de lesões digitais em vacas da raça Holandesa mantidas em sistema "free-stall". PUBVET, Londrina, V. 4, N. 7, Ed. 112, Art. 756, 2010.

\section{RESULTADOS E DISCUSSÃO}

Todos os animais dos dois grupos apresentaram pelo menos uma lesão digital, sendo visualizadas lesões múltiplas na maioria dos animais. A freqüência dos tipos e a distribuição das lesões, entre os membros torácicos e pélvicos, encontradas nas vacas de primeira lactação (Grupo P) e nas vacas entre a segunda e sétima lactação (Grupo M) estão sumariadas na Tabela 2.

Tabela 2. Tipos e distribuição das lesões, entre os membros torácicos (MT) e pélvicos (MP), encontrados nas vacas primíparas (Grupo $P, n=34$ ) e multíparas (Grupo M, $\mathrm{n}=51$ ) da raça Holandesa.

\begin{tabular}{lcccc}
\hline \multicolumn{1}{c}{ TIPOS DE LESÕES } & \multicolumn{3}{c}{ GRUPO P } & GRUPO M \\
\multicolumn{1}{c}{ M. T. } & M. P. & M. T. & M. P. \\
& $(\%)$ & $(\%)$ & $(\%)$ & $(\%)$ \\
\hline Erosão axial & 34,4 & 31,4 & 36,7 & 23,1 \\
Sola dupla & 22,7 & 24,1 & 13,3 & 17,5 \\
Erosão de talão & 13,0 & 16,1 & 20,5 & 17,2 \\
Doença da linha branca & 11,7 & 6,7 & 9,6 & 9,0 \\
Laminite & 6,7 & 7,2 & 9,0 & 12,0 \\
Hemorragia de sola & 6,5 & 7,2 & 5,0 & 9,1 \\
Rachadura horizontal do estojo córneo & 4,0 & 0,6 & 2,6 & \\
Dermatite digital papilomatosa & & 3,8 & & 4,0 \\
Dermatite interdigital & 1,0 & 1,7 & 1,0 & 4,1 \\
Pinça longa / talão baixo & & 0,6 & 2,0 & 3,0 \\
Úlcera de sola & & 0,6 & & 0,4 \\
Abscesso sub-solear & & & & 0,6 \\
Flegmão interdigital & & & & \\
Rachadura vertical do estojo córneo & & & & 0,2 \\
* $\mathrm{n}=$ número de animais & & &
\end{tabular}

$\mathrm{n}=$ número de animais

Durante o período experimental a produção média, das vacas primíparas foi de 30 litros de leite/dia, e das vacas multíparas foi de 37 litros de leite/dia. A freqüência e distribuição clínica das lesões podais foram semelhantes nos grupos $P$ e $M$, provavelmente pela atuação semelhante dos fatores 
SILVA, A.A.M.et al. Prevalência e distribuição clínica de lesões digitais em vacas da raça Holandesa mantidas em sistema "free-stall". PUBVET, Londrina, V. 4, N. 7, Ed. 112, Art. 756, 2010.

predisponentes como: umidade, abrasão e matéria orgânica, entretanto esses resultados discordam de estudos que evidenciaram a maior incidência das lesões em vacas multíparas, acima de quatro anos de idade, em relação às vacas primíparas com menos de três anos de idade ${ }^{3}$, a correlação positiva entre o aumento do número de lesões podais e o número de partos das vacas, ${ }^{9}$ e ainda, a influência direta exercida pela idade na ocorrência de problemas de casco. ${ }^{10,11}$

Erosão axial, sola dupla, erosão do talão, doença da linha branca e laminite foram as principais lesões encontradas nos animais de ambos os grupos (Figura A), correspondendo a $87 \%$ e $84 \%$ dos casos nos grupos $\mathrm{P}$ e $\mathrm{M}$, respectivamente. Esse achado reafirma os dados encontrados na literatura $1,9,11$ que descrevem estas, como as lesões de maior prevalência neste sistema de produção. Contudo, discorda de estudos que apontam a maior prevalência da dermatite digital. ${ }^{3,12}$

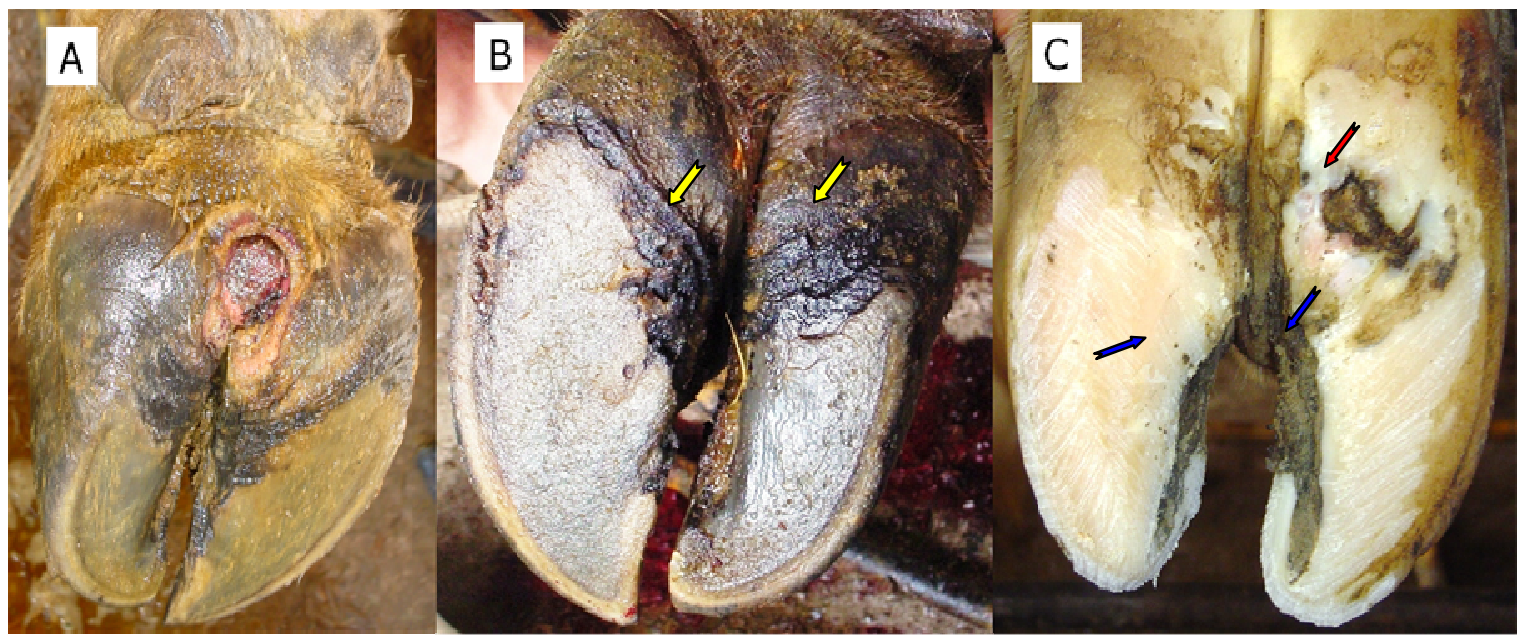

Figura 1. A - Dermatite Digital. B - Erosão de Talão (setas amarelas). C Úlcera de Sola (seta vermelha) e Doença da Linha Branca (setas azuis). 
SILVA, A.A.M.et al. Prevalência e distribuição clínica de lesões digitais em vacas da raça Holandesa mantidas em sistema "free-stall". PUBVET, Londrina, V. 4, N. 7, Ed. 112, Art. 756, 2010.

Um total de 672 e 927 lesões foram evidenciadas nos animais dos grupos P e $M$, respectivamente. Destas, $56 \%$ (373/672) estiveram presentes nos membros pélvicos dos animais do grupo $P$ e 58\% (536/927) nos animais do grupo $M$, evidenciando assim, a maior incidência das lesões nos membros pélvicos, em ambos os grupos, o que corrobora com os resultados de estudos que afirmam serem os membros pélvicos mais afetados que os membros torácicos, devido à maior distribuição do peso corpóreo das vacas sobre esses membros. ${ }^{1,3,12}$

Um estudo com bovinos de leite em lactação constatou predominância das lesões nos dígitos laterais dos membros pélvicos em relação aos dígitos mediais. ${ }^{1}$ Fato também observado neste experimento, pois, os dígitos laterais dos membros pélvicos foram acometidos com maior freqüência, em ambos os grupos estudados, correspondendo respectivamente a 49,9\% (186/373) e $46,4 \%(249 / 536)$ de todas as lesões encontradas nos membros pélvicos dos animais dos grupos $\mathrm{P}$ e $\mathrm{M}$. Contudo, não houve diferença na incidência das lesões entre os dígitos laterais e mediais, dos membros torácicos, dos animais de ambos os grupos, contrariando autores que relatam 0 maior comprometimento dos dígitos mediais nos membros torácicos. ${ }^{1}$ Esse resultado provavelmente seja conseqüência do manejo adotado na propriedade, que só prioriza o casqueamento preventivo nos dígitos dos membros pélvicos, limitando o casqueamento dos membros torácicos apenas quando os animais apresentavam alterações nos mesmos.

A prevalência das lesões interdigitais, compostas por flegmão e dermatite interdigital, foram $11 \%(73 / 672)$ e $16 \%$ (147/927) no total das lesões observadas nos animais dos grupos $\mathrm{P}$ e $\mathrm{M}$ respectivamente, sendo semelhantes aos resultados obtidos em vacas lactantes criadas em sistema semi-intensivo ${ }^{4}$ e inferior às incidências de 26,8 e 25\% dessas lesões em estudos conduzidos com vacas leiterias mantidas respectivamente em regime intensivo ${ }^{4}$ e semi-extensivo. ${ }^{3}$

Os membros direitos, tanto torácicos quanto pélvicos, dos animais de ambos os grupos foram mais acometidos que os membros esquerdos. Essa 
SILVA, A.A.M.et al. Prevalência e distribuição clínica de lesões digitais em vacas da raça Holandesa mantidas em sistema "free-stall". PUBVET, Londrina, V. 4, N. 7, Ed. 112, Art. 756, 2010.

maior incidência, provavelmente, seja decorrente da diminuição da circulação nestes membros, devido à pressão mecânica exercida sobre os mesmos durante o decúbito esternal, normalmente adotado pelos animais em repouso. ${ }^{3}$

Claudicação foi observada em 11 (32\%) animais do grupo $\mathrm{P}$, destes $73 \%$ (8/11) apresentaram grau II, 9\% (1/11) grau III e 18\% (2/11) o grau IV de severidade. Já no grupo de vacas multíparas a claudicação foi observada em $36(73 \%)$ animais, sendo distribuída quanto à severidade em 39\% (14/36) grau II, 42\% (15/36) grau III, 17\% (6/36) grau IV e 2\% (2/36) grau V. Estes dados correlacionam a presença de lesões com o agravamento dos graus de claudicação no grupo $M$, corroborando com outros autores. ${ }^{1,4,13}$ Entretanto, as lesões podais encontradas nos animais do grupo $P$ aparentemente não agravaram o grau de claudicação destes animais.

Analisando os dados obtidos neste estudo conclui-se que as lesões podais incidiram de forma semelhante nos dois grupos, principalmente nos dígitos dos membros pélvicos, sendo a erosão axial, sola dupla e erosão de talão as enfermidades podais mais prevalentes. Contudo, essas lesões influenciaram de forma diferente, quanto à claudicação, os animais dos dois grupos, sendo evidenciados graus de claudicação maiores nos animais do grupo M.

\section{REFERÊNCIAS BIBLIOGRÁFICAS}

1. SOUZA, F.A.A., Prevalência de lesões podais em vacas da raça Holandesa Preta e Branca, em lactação, mantidas em regime de estabulação permanente ("Free-stall" e "Tie-stall"). Universidade Estadual Paulista, 74p. (Tese de Doutorado), 2001.

2. SOUZA, R.C.; FERREIRA, P.M.;MOLINA, L.R.; CARVALHO, A.U.; FACURY FILHO, E.J. Arq. Bras. Med. Vet. Zootec., 58(6):982-987, 2006.

3. SILVA, L.A.F.; SILVA, L.M.; ROMANI, A.F.; RABELO, R.E.; FIORAVANTI, M.C.S.; SOUZA, T.M.; SILVA, C.A. Ciência Animal Bras., 2(2):119-196, 2001.

4. SOUZA, R.C.; CARVALHO, A.U.; FERREIRA, P.M.; FACURY FILHO, E.J.; FERREIRA, R.G.; COSTA, C.O.; MOURTHE NETO, A. Ciência Animal Bras., 8(4):823-831, 2007.

5. NICOLETTI, J.L.M. Manual de podologia bovina. São Paulo: Manole, 2004, 126p.

6. RUSSEL, A.M.; ROWLANDS, G.J.; SHAW, S.R.; WEAVER, A.D. Vet. Rec., 111(7):155-160, 1982.

7. SHEARER, J.K. Bov. Pract., 32(1), 1998.

8. FERREIRA, P.M.; LEITE, R.C.; CARVALHO, A.V.; FACURY FILHO, E.J.; SOUZA, R.C.; FERREIRA, M.G. Arq. Bras. Med. Vet. Zootec., 56(5):589-594, 2004.

9. NICOLETTI, J.L.M.; SOUZA, F.A.A.; THOMASSIAN, A.; HUSSNI, C.A.; ALVES, A.L.G. Rev. Educ. Contin. CRMV-SP , 4(2):24-32, 2001.

10. BAGGOT, D.G., RUSSEL, A. M. Br. Vet. J., 137:113-132, 1981. 
SILVA, A.A.M.et al. Prevalência e distribuição clínica de lesões digitais em vacas da raça Holandesa mantidas em sistema "free-stall". PUBVET, Londrina, V. 4, N. 7, Ed. 112, Art. 756, 2010.

11. MOlinA, L.R.; CARVALHO, A.U.; FACURY FILHO, E.J.; FERREIRA, P.M. Arq. Bras. Med. Vet. Zootec., 51(2):149-152, 1999.

12. MARTINS C.F; SARTI, E. Ensaios e Ciências, 6(2):111-135, 2002.

13. BERRY, S.L. Escore de locomoção para vacas de leite. Disponível em: <http://www.availa4.com/locomotion/pdf>, acessado em 26/10/2002. 